\title{
The Relationship Between the Score system and Performance Determinants of Modern Pentathlon
}

\author{
Seunghun Lee ${ }^{\mathrm{a}}$ \& Hyongjun Choi $^{\mathrm{b}}$ * \\ ${ }^{a}$ Department of Sport Science, Korea Institute of Sport Science, Seoul, Korea \\ ${ }^{b}$ Physical Education Department, Dankook University, Yongin, Korea
}

\begin{abstract}
The rules of modern pentathlon, in which the final ranking is determined by the results of swimming, fencing, riding, and laser-run, have been revised and managed by UIPM (International Modern Pentathlon Union). This study was conducted to evaluate the relationship between the score characteristics of five sports events and their influences on the final ranking, and to improve the UIPM's score conversion system, by analyzing the UIPM Level 1 final records of three years before and after 2017 when the swimming score system was revised. Independent t-tests revealed that laser-run performances improved significantly after the revision in 2017, while swimming performances got worse. The results of multiple regression analysis obtained through the four conversion scores showed that all four independent variables were significant. Considering the characteristics of Modern Pentathlon In Which The Importance Of Each Component Event Should Be Similar This Study Showed that the relative importance was biased towards fencing and the swimming event was neglected. Therefore, it seems necessary to change the swimming conversion score system to assess the players of modern pentathlon accurately and fairly.
\end{abstract}

Key words: performance analysis, modern pentathlon, UIPM, combined sports, game outcome, relative importance

\section{Introduction}

Every sport has its own rules (Lee, 2019). The rules present the person who participates in game about which play is allowed and which behavior is prohibited and these rules set a standard which judge who is winner or loser (MacRae, 2020). These rules of sports competition have been revised and modified by various

Submitted : 5 October 2020

Revised : 17 December 2020

Accepted : 30 December 2020

Correspondence : chj2812@dankook.ac.kr factors, including safety, tradition, competition, media, political and economic situations (Lee, 2016). The sports community has continued to implement revisions to the rules considering the improvement of performance. In addition, with the introduction of advanced sports science and technology, athletes performance has steadily improved, and records continue to be renewed (Choi, Kim, Lee, Park \& Yeom, 2014).

These sports rules approve athletes records through the value of honesty and fairness, and prevent and 
regulate athletes violations of them through the enactment and enforcement of systems and law. Everyone tries to win, but winning itself is not the only goal. It is a basic virtue and a core value of the sports that the athletes compete honestly, while referees make accurate judgments based on the fair rules (Kim, 2012). In particular, the events scored based on the results of the competition require fairness and equality as core values. Therefore, it will be necessary to eliminate the factors that may cause unfairness due to the rules of the game, which could determine the victory and defeat of the hard-working player by participating in the game, or directly related to the ranking (Park \& Park, 2012). The passion for recording and analyzing sports scientifically and systematically has been in sports continually by the sports scientists, leaders and athletes, and the officials who are engaged in these sport (Hughes \& Franks, 2004). Analyzing the sports game scientifically gives a lot of help in establishing and setting the training plans for the future and improving the performance of athletes and teams. In particular, it is necessary to analyze the contents of sport games objectively and systematically in order to improve the athletic performance. The reason is that this kind of analysis can extract the factors that influence on the athletic performance and winning and defeating (Hughes \& Franks, 2004).

In addition to the accuracy of the decisions taking place in the course of the competition, various efforts are needed to analyse the systems involved in the competition and to improve the performance, being required to establish and revise the competition rules on which these contents are based, which would objectify the fairness and equality of the sporting events (Dabbagh \& Edgar, 2020). Modern pentathlon is the traditional Olympic sport that has been held since the fifth Stockholm Olympic Games (1912), which is compounded competition that decides the ranking by the total scores from five games including épée rule fencing, 200m freestyle swimming, obstacle riding, $3.2 \mathrm{~km}$ track and 10m shooting (KMPF, 2018).
The scoring for each event of modern pentathlon is based about 1,000 points, which serves as a sort of par in golf game. Athletes gain points for their performance in each event and the competitors are ranked according to their score. Starting times for the last event are staggered so that the first person to cross the finish line is the winner. Finally, all the scores of all the participants are combined to give the overall total. By applying the handicap start, the competitor who passes the finish line for the first will be the final winner of the pentathlon (UIPM, 2017). The competition of fencing, unlike other games is a round-robin, meaning each competitor will face all the other competitors once. Therefore, the score of the fencing competition has a great influence on the final result (Lim, Yoon, Jeong \& Kim, 2018). The changes in performance before and after revision of the rules of the combined sports have shown that various supplementary measures should be prepared to supplement the differences in techniques at the sporting events that need skills compared to those requiring basic physical strength (Le Meur, Hausswirth, Abbiss, Baup \& Dorel, 2010).

There is a possibility that the importance of certain events could be overestimated depending on the scoring method and system in the process of converting the records for each detailed event into scores during the combined sports, which allows players who are biased in certain events to perform well. Although much effort will be made to improve the performance of events that are biased in importance among detailed events, there is a possibility that the players will neglect them, which brings down the overall performance. Therefore, the rules and system of sports competition should move in a way that does not downgrade performance through scientific analysis. If the scoring systems and rules have been revised for certain reasons, a comprehensive and systematic comparison of records and scores for each category must be made. For this verification process, a study on the scoring system is required. This study compared the official competition records of the World Cup and World Championships finals, which were the 
UIPM Level 1 competition for three years before and after 2017, when the modern pentathlon swimming score was revised. According to the results, the scoring characteristics of fencing, swimming, riding, and laser-run events among the modern pentathlon events were revealed to have a relationship with the final ranking.

\section{Methods}

\section{Research material}

This study collected and analyzed the data for each competitor of the modern pentathlon final competition, which was released on the UIPM's website. Before the revision of UIPM's evaluation method, data on 574 men's and 545 women's cases were obtained from 18 competitions, and 603 men's and 594 women's cases were collected and analyzed in 18 competitions after the revision. Among the classified data, incomplete ones were excluded, and repeated data from the same competitor who advanced to the finals were included in the analysis.

\section{Variables}

The statistics with regard to the players' game performances provided by UIPM were as follows; fencing rankings, fencing's ratio of rise, fencing conversion scores, swimming records, swimming rankings, swimming conversion scores, equestrian rankings, equestrian conversion scores, laser-run records, laser-run rankings, laser-run conversion scores, and shooting times. The evaluation of modern pentathlon is largely divided into two categories: record evaluation method and score evaluation method scored in the game. Competitions that use the record evaluation method, which measures the athletes record in seconds, include swimming and laser runs. Swimming, laser-runs, fencing and riding are another competitions that use the latter criteria, which give points to the participants. Among them, swimming and laser-run use both evaluation methods because they apply conversion scores based on records. Table 1 shows a total of two record variables and four score variables.

Table 1. Definitions and characteristics of variables.

\begin{tabular}{ccc}
\hline \hline Variables & Definitions & Characteristic (Unit) \\
\hline$Y$ & Final ranking & Ranking (place) \\
$X_{1}$ & Swimming records & Record (seconds) \\
$X_{2}$ & Laser-run records & Record (seconds) \\
$X_{3}$ & Fencing points & Points \\
$X_{4}$ & Swimming points & Points \\
$X_{5}$ & Riding points & Points \\
$X_{6}$ & Laser-run points & Points \\
\hline \hline
\end{tabular}

\section{UIPM score conversion regulation}

The fencing game of modern pentathlon is a round-robin tournament, with a single touch deciding each match. The bout lasts for a minute, the winner of the game is the first fencer to score a hit. If either of the two fails to get a hit, both players register a defeat. Seventy percent of bouts won correspond to 1000 pentathlon points. Each victory above or below $70 \%$ is worth a certain point value, and this number depends on the number of competitors, which means 25 victories out of 35 bouts (70\%) is converted to 1000 Pentathlon points. Pentathlonists may swim any stroke or style. Each one second UIPM has revised the swimming score conversion rules that had awarded +3 or -3 per second based on the competition records (UIPM. 2017).

The new scoring system has been applied to modern pentathlon since 2017. A time of 2:30 earns $250 \mathrm{MP}$ points. Each one second will be awarded +2 or -2 points according to the points table for swimming. The riding event in modern pentathlon includes jumping over 120 $\mathrm{cm}$ tall obstacles. The competitor has a certain time limit to complete the course, and the time limit is set according to the length of the course. For each mistake 
the rider loses points. After 2 refusals to jump, the rider must try to jump the next obstacle. A fall of the rider from the horse or if they both fall is a 60-point penalty. The riding will be terminated after two falls, and the rider loses 100 points. Each second over the time limit means a deduction of 4 points (UIPM. 2017).

The player who passes the obstacle without any deduction is given 300 points. The laser-run event consists of 20 laser-shootings and $3.2 \mathrm{Km}$ running. Depending on the overall score of the previous three events including fencing, swimming, and equestrian, it will be carried out in a 'handicap start' manner, which will differ in the starting time. Running a total of 3,200 meters, the player repeatedly hits five targets in the middle with an unlimited 50-second laser gun shot. In other words, the total number of shooting targets will be 20. The scoring system will give 500 points based on 13'20" from start to finish line. One second faster, one point is added, and one second slower, one point is lost. In the case of shooting, all five targets must be hit with a 50 second limit at one shooting location. If the player hits all of the targets, he or she can start immediately. The first player to arrive at the finish line wins the game (UIPM. 2017).

\section{Data processing}

Data cleaning and pre-processing were carried out using Excel. The SPSS Statistics 20 program was used for the statistical processing of this data. First, for the record variables between 2014 and 2019, descriptive statistics and independent t-test analysis were conducted to examine differences in official records between groups before and after the revision of the UIPM rules in 2017. Second, in order to evaluate the relative importance of the conversion score of each event that contributes to the final ranking between groups through score variables, Pearson's correlation was applied and multiple regression analysis was conducted with independent variables.

\section{Relative importance evaluation}

\section{(1) Analysis of dependent variables on a rank order scales}

The use of variables with the characteristics of the hierarchy in parametric statistics can cause problems such as statistical distortion (Kuzon, Urbanchek \& McCabe, 1996). Even though the summated scale has the characteristics of a hierarchy, it is common to use it like an equidistant scale variable, which is frequently used in parametric statistics (Stevens, 1951). One of the assumptions of regression analysis is that the dependent variable must be a continuous isometric measure. However, as Berry (1993) found, the perfect continuous isometric scale was not as much as expected, but rather more discontinuous isometric scale. For this reason, many empirical studies that perform regression analysis often use discontinuous isometric values as a dependent variable. Although there is a gap between each value that makes up the variable, unlike common hierarchical variables, it provides meaningful information about differences in variable values. For this reason, in the course of statistical analysis, a total scale variable with relatively more continuous characteristics than a discontinuous isometric is often analysed as a dependent variable without serious problems (Michell, 2008). In this study, the final ranking was used as an equidistant scale to analyze the data, through which we evaluated the relative importance of the results of each event of the athletes who participated in the modern pentathlon to the final ranking.

\section{(2) Relative effectiveness size between variables using standardized regression coefficient}

The evaluation of the importance of variables in multiple regression is very relied on standardized regression coefficient. It can be interpreted that standardized variation of the response variables which is about increase of the variables which were standardized by a specific explanatory variables (Moh, Han, Yeon \& Kang, 2015). For standardized regression 
coefficient about the explanatory variables, all other explanatory variables except those variables are maintained constantly. Standardization of the coefficient is usually done to answer the question of which of the independent variables have a greater effect on the dependent variablein a multiple regression analysis, when the variables are measured in different units of measurement(for example, income measured in dollars and family size measured in number of individuals). Values for standardized and unstandardized coefficients can also be derived subsequent to either type of analysis.

Therefore, it could be utilized simply and efficiently when comparison is needed. This study implemented a Pearson's correlation analysis between the variables. Multicollinearity refers to a situation in which two or more explanatory variables in a multiple regression model are highly linearly related. To measure multicollinearity, the correlation structure of variables can be investigated, such as the Variance Inflation Factor, Tolerance, and the method of investigating the state index. In addition, to solve multicollinearity problems, other estimation methods such as eliminating problematic explanatory variables or analyzing principal components (PCA) or Ridge regression may be used. In this study we used it to figure out the relationship between the response (subsequent) variable, the final rank and the converted score of each detail events, which was the four explanatory (independent) variables. It was displayed to interpret at the standardized regression coefficient at the standardized regression coefficient graph (Peranginangin \& Alamsyah, 2017).

\section{Results}

\section{Match frequency}

Table 2 shows the results of descriptive statistics such as minimum and maximum values, mean and standard deviation for the modern pentathlon records. According to UIPM data, 1,177 men and 1,139 women participated in modern pentathlon between 2014 and 2019. All of 574 men and 545 women participated in the modern pentathlon before revision of UIPM rules, while 603 men and 594 women participated after the revision of the rules.

Table 2. Descriptive statistics of the variables.

\begin{tabular}{clrrrrrr}
\hline \hline \multirow{2}{*}{ Variables(unit) } & \multicolumn{3}{c}{ Before } & \multicolumn{3}{c}{ After } \\
\cline { 2 - 7 } Male & $\mathrm{N}$ & Mean & $\mathrm{SD}$ & $\mathrm{N}$ & \multicolumn{1}{c}{ Mean } & \multicolumn{1}{c}{ SD } \\
\hline & (place) & 574 & 17.410 & 9.794 & 603 & 17.400 & 9.903 \\
& $X_{1}$ (s) & 574 & 124.970 & 4.202 & 603 & 127.100 & 4.514 \\
& $X_{2}$ (s) & 574 & 701.988 & 32.907 & 603 & 695.610 & 30.131 \\
& $X_{3}$ (Points) & 574 & 204.970 & 23.269 & 603 & 204.920 & 23.084 \\
& $X_{4}$ (Points) & 574 & 325.560 & 12.603 & 603 & 296.270 & 9.011 \\
& $X_{5}$ (Points) & 574 & 281.680 & 19.464 & 603 & 284.010 & 16.752 \\
& $X_{6}$ (Points) & 574 & 598.360 & 32.918 & 603 & 604.830 & 30.126 \\
\hline$Y$ (place) & 545 & 16.600 & 9.379 & 594 & 17.050 & 9.609 \\
Female & 545 & 139.206 & 5.442 & 594 & 139.610 & 5.954 \\
$X_{1}$ (s) & 545 & 791.273 & 37.490 & 594 & 781.540 & 38.049 \\
$X_{2}$ (s) & $X_{3}$ (Points) & 545 & 204.920 & 24.503 & 594 & 205.400 & 25.511 \\
$X_{4}$ (Points) & 545 & 282.850 & 16.315 & 594 & 271.260 & 11.895 \\
$X_{5}$ (Points) & 545 & 282.410 & 18.944 & 594 & 282.400 & 18.409 \\
$X_{6}$ (Points) & 545 & 509.100 & 37.487 & 594 & 518.890 & 38.063 \\
\hline \hline
\end{tabular}

${ }^{*} \mathrm{p}<.05, Y$ : Final ranking, $X_{1}$ : Swimming records, $X_{2}$ : Laser-run records, $X_{3}$ : Fencing points, $X_{4}$ : Swimming points, $X_{5}$ : iding points, $X_{6}$ : Laser-run points 


\section{Group comparisons analysis}

Utilizing both male and female's the modern pentathlon swimming records and laser run records, we studied the differences between the groups before and after revising the way of converting the score.

Table 3 reveals the result from statistical analysis comparing the competition records before and after the revision among the groups. The outcome by implementing independent sample t-verification for the comparison between groups is as follows: Male's swimming record ( $t=-8.304, d f=1175, p=.000$ ), Male laser-run record ( $t=3.467, d f=1153.422, p=.001)$, and Female's laser-run records $(t=4.345, d f=1137, p=.000)$. While it showed a significant difference statistically $(p<.05)$, we couldn't find any difference in female's swimming records $(t=-1.185, d f=1137$, $p=.236$ ). The men's and women's records at laser-run events got better after the revision (male=695.60, female=781.54), which showed relatively lower average scores than before (male $=701.99$, female $=791.27$ ). On the other hand, however, the revised method of scoring system in swimming competitions was found to worsen the existing men's and women's records after the revision, which showed relatively higher average scores after the revision (127.08 for male, 139.61 for female) rather than before (124.97 for male, 139.21 for female). Figure 1 shows the changes of records in swimming and laser-run events by year.

Analysis of the relative importance of each event

(1) Correlation analysis of conversion points by each event

A correlation analysis on those variables including

Table 3. The competition records before and after the revision among the groups

\begin{tabular}{|c|c|c|c|c|c|c|c|c|}
\hline & & Group & $\mathrm{N}$ & Mean & SD & t-value & $d f$ & p-value \\
\hline \multirow{4}{*}{ Male } & \multirow[b]{2}{*}{$X_{1}$} & Before & 574 & 124.970 & 4.202 & \multirow{2}{*}{$-8.304 *$} & \multirow{2}{*}{1175} & \multirow[b]{2}{*}{.001} \\
\hline & & After & 603 & 127.076 & 4.487 & & & \\
\hline & \multirow{2}{*}{$X_{2}$} & Before & 574 & 701.988 & 32.907 & \multirow{2}{*}{$3.467 *$} & \multirow{2}{*}{1153.422} & \multirow{2}{*}{.001} \\
\hline & & After & 603 & 695.602 & 30.139 & & & \\
\hline \multirow{4}{*}{ Female } & \multirow{2}{*}{$X_{1}$} & Before & 545 & 139.206 & 5.442 & \multirow{2}{*}{-1.185} & \multirow{2}{*}{1137} & \multirow{2}{*}{.236} \\
\hline & & After & 594 & 139.608 & 5.950 & & & \\
\hline & \multirow{2}{*}{$X_{2}$} & Before & 545 & 791.273 & 37.490 & \multirow{2}{*}{$4.345^{*}$} & \multirow{2}{*}{1137} & \multirow{2}{*}{.001} \\
\hline & & After & 594 & 781.535 & 38.051 & & & \\
\hline
\end{tabular}

${ }^{*} \mathrm{p}<.05, Y$ : Final ranking, $X_{1}$ : Swimming records, $X_{2}$ : Laser-run records
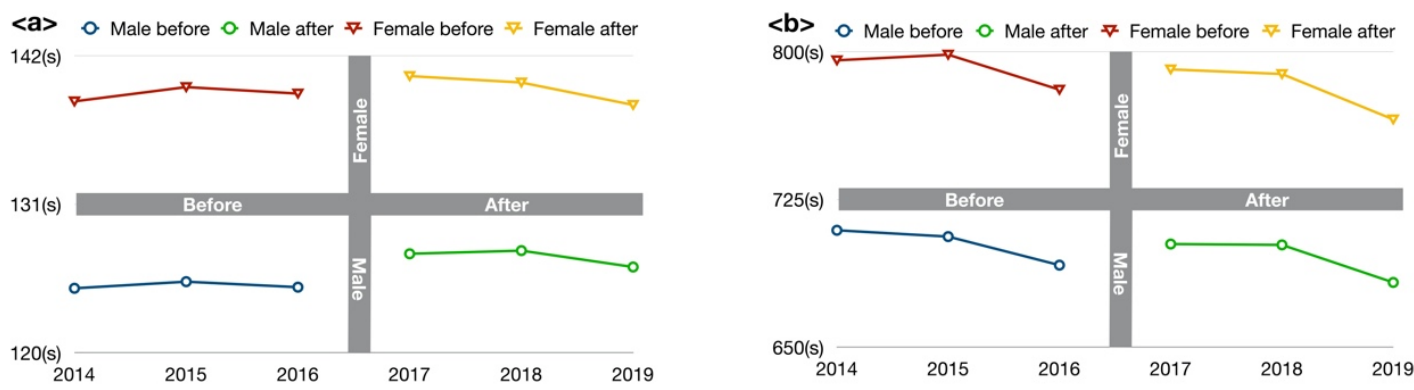

Figure 1. Changes of records in swimming and laser-run events by year. (a) Swimming, (b)Laser-run 
fencing, swimming, riding and laser run scores was implemented in order to analyze the relative importance of each event according to the revised scoring system of the modern pentathlon. Table 4 showed the showing the positive correlation. This study confirmed that fencing scores had a high correlation with total rankings in both before and after revision.

\section{(2) Multiple regression analysis of converting points by each event}

Table 5 presents the results which was calculated through multiple regression analysis to determine the degree in which the scores of each men's event in modern pentathlon gave influence to the final ranking which was a dependent variable. The power of explanation by regression model was $71.8 \%(=.718)$ for males, $67.5 \%\left(R^{2}=.675\right)$ for males, $72.0 \%\left(R^{2}=.720\right)$ for females, and $74.2 \%\left(R^{2}=.742\right)$ for females, respectively.

Considering the absolute value of standardized regression coefficient, we could find the significance of regression equation meaningful with the values before and after the revision $(F=362.985)$, after the revision $(F=310.144)$, before and after the revision ( $F=346.976)$, and after the revision $(F=424.325)$. All of the VIF values that can indicate the degree of multicollinearity, are less than 10 , through which we can confirm that there is no multicollinearity among the variables. The revised coefficient of determination, 71.6\% (Adjusted $R^{2}=.716$ ), 67.3\% (Adjusted $R^{2}=.673$ ), $71.8 \%$ (Adjusted $R^{2}=.718$ ) before the revision, and 74.1\% (Adjusted $R^{2}=.741$ ) after the revision explain the movement of the independent variables as an indicator of evaluating the validity of the regression equation. By using standardized regression coefficient, the ranking of impact size for each sport's score and records on the final scores in men's relative importance sequence before and after revision are as follows; 1) Fencing ( $b=-.597, b=-.632$ ), 2) Laser-run ( $b=-.402, b=-.334), 3$ ) riding ( $b=-.324, b=-.269)$, 4) Swimming $(b=-.163$, $b=-.087$ ). In addition, women's relative importance

Table 4. Pearson's correlations between the independent and dependent variables

\begin{tabular}{|c|c|c|c|c|c|c|c|}
\hline & Variables & & $\overline{Y Y}$ & $X_{3}$ & $X_{4}$ & $\bar{X}_{5}$ & $\bar{~} X_{6}$ \\
\hline \multirow{10}{*}{ Male } & \multirow{5}{*}{ Before } & $Y$ & 1 & & & & \\
\hline & & $X_{3}$ & $-.627 * *$ & 1 & & & \\
\hline & & $X_{4}$ & $-.165 * *$ & .041 & 1 & & \\
\hline & & $X_{5}$ & $-.427 * *$ & .060 & .031 & 1 & \\
\hline & & $X_{6}$ & $-.445^{* *}$ & .009 & $-.082 *$ & $.157 * *$ & 1 \\
\hline & \multirow{5}{*}{ After } & $Y$ & 1 & & & & \\
\hline & & $X_{3}$ & $-.680^{* *}$ & 1 & & & \\
\hline & & $X_{4}$ & $-.142^{* *}$ & $.094^{*}$ & 1 & & \\
\hline & & $X_{5}$ & $-.385^{* *}$ & $.117^{* *}$ & -.014 & 1 & \\
\hline & & $X_{6}$ & $-.386 * *$ & .027 & -.004 & $.129 * *$ & 1 \\
\hline \multirow{10}{*}{ Female } & \multirow{5}{*}{ Before } & $Y$ & 1 & & & & \\
\hline & & $X_{3}$ & $-.575^{* *}$ & 1 & & & \\
\hline & & $X_{4}$ & $-.216^{* *}$ & -.071 & 1 & & \\
\hline & & $X_{5}$ & $-.416^{* *}$ & .046 & .011 & 1 & \\
\hline & & $X_{6}$ & $-.456 * *$ & .045 & -.036 & .064 & 1 \\
\hline & \multirow{5}{*}{ After } & $Y$ & 1 & & & & \\
\hline & & $X_{3}$ & $-.538^{* *}$ & 1 & & & \\
\hline & & $X_{4}$ & $-.278^{* *}$ & .058 & 1 & & \\
\hline & & $X_{5}$ & $-.451^{* *}$ & .063 & .028 & 1 & \\
\hline & & $X_{6}$ & $-.478^{* *}$ & -.066 & .062 & .068 & 1 \\
\hline
\end{tabular}

${ }^{*} \mathrm{p}<.05,{ }^{*} \mathrm{p}<.01, Y$ : Final ranking, $X_{3}$ : Fencing points, $X_{4}$ : Swimming points, $X_{5}$ : iding points, $X_{6}$ : Laser-run points 
sequence before and after revision is follwed by these; 1) Fencing ( $b=-.539, b=-.533)$, 2) Laser-run $(b=-.418$, $b=-.475)$, 3) riding ( $b=-.361, b=-.379)$, 4) Swimming ( $b=-.267, b=-.207$ ).

It was also confirmed that all of the four independent variables for both men's and women's events were significant. In the case of men's events, the fencing was the most affected event. As for swimming, riding and laser-runs were also affected after the revision. The analysis of the women's events also showed that fencing event was the most affected. In the case of riding and laser-runs, there was a slight increase in influence after the revision. A lack of influence was on the final score due to the change in converting way of swimming scores which led to the lower discrimination.

\section{Discussion and proposal}

This study compared the scoring systems before the revision and those after the revision in the modern pentathlon, which tried to propose the suitability of the system for converting the scores through showing the relative importance of the detailed categories. On the basis of the results of this study, we would discuss the relationship of each factor as follows.

First, the records got better after the revision at laser-run events. On the other hand, swimming records for both men's and women's events showed little or no change after the revision.

Second, the ranking for each event according to its relative importance in both men's and women's events was fencing, laser-run, riding and swimming in order.

Table 5. Summary of the multiple-regression(enter) results.

\begin{tabular}{|c|c|c|c|c|c|c|c|c|c|}
\hline & Variables & & 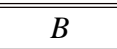 & SE & $\overline{\beta \beta}$ & 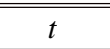 & - & $r$ & VIF \\
\hline \multirow{12}{*}{ Male } & \multirow{6}{*}{ Before } & $Y$ & 227.736 & 7.680 & & 29.652 & .001 & & \\
\hline & & $X_{3}$ & -.251 & .009 & -.597 & -26.773 & .001 & -.747 & 1.005 \\
\hline & & $X_{4}$ & -.127 & .017 & -.163 & -7.298 & .001 & -.293 & 1.010 \\
\hline & & $X_{5}$ & -.163 & .011 & -.324 & -14.341 & .001 & -.515 & 1.031 \\
\hline & & $X_{6}$ & -.120 & .007 & -.402 & -17.794 & .001 & -.598 & 1.033 \\
\hline & & & & & & \multicolumn{2}{|c|}{$R^{2}$ (Adjusted $\left.R^{2}\right)=.718(.716)$} & \multicolumn{2}{|c|}{$F=362.985(p<.001)$} \\
\hline & \multirow{6}{*}{ After } & $Y$ & 212.887 & 9.592 & & 22.194 & .001 & & \\
\hline & & $X_{3}$ & -.271 & .010 & -.632 & -26.773 & .001 & -.738 & 1.023 \\
\hline & & $X_{4}$ & -.096 & .026 & -.087 & -3.712 & .001 & -.150 & 1.010 \\
\hline & & $X_{5}$ & -.159 & .014 & -.269 & -11.368 & .001 & -.422 & 1.031 \\
\hline & & $X_{6}$ & -.110 & .008 & -.334 & -14.206 & .001 & -.502 & 1.017 \\
\hline & & & & & & \multicolumn{2}{|c|}{$R^{2}\left(\right.$ Adjusted $\left.R^{2}\right)=.675(.673)$} & \multicolumn{2}{|c|}{$F=310.114(p<.001)$} \\
\hline \multirow{11}{*}{ Female } & \multirow{6}{*}{ Before } & 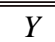 & 207.576 & 5.913 & & 35.107 & 2.001 & & \\
\hline & & $X_{3}$ & -.214 & .009 & -.559 & -24.443 & .001 & -.725 & 1.009 \\
\hline & & $X_{4}$ & -.154 & .013 & -.267 & -11.701 & .001 & -.450 & 1.007 \\
\hline & & $X_{5}$ & -.179 & .011 & -.361 & -15.798 & .001 & -.562 & 1.006 \\
\hline & & $X_{6}$ & -.104 & .006 & -.418 & -18.272 & .001 & -.618 & 1.007 \\
\hline & & & & & & \multicolumn{2}{|c|}{$R^{2}\left(\right.$ Adjusted $\left.R^{2}\right)=.720(.718)$} & \multicolumn{2}{|c|}{$F=346.976(p<.001)$} \\
\hline & \multirow{5}{*}{ After } & $Y$ & 221.788 & 6.061 & & 36.593 & .001 & & \\
\hline & & $X_{3}$ & -.201 & .008 & -.533 & -25.334 & .001 & -.722 & 1.013 \\
\hline & & $X_{4}$ & -.167 & .017 & -.207 & -9.872 & .001 & -.377 & 1.008 \\
\hline & & $X_{5}$ & -.198 & .011 & -.379 & -18.025 & .001 & -.596 & 1.010 \\
\hline & & $X_{6}$ & -.120 & .005 & -.475 & -22.556 & .001 & -.681 & 1.014 \\
\hline
\end{tabular}

$r$ : Partial correlation coefficient, Final ranking, Fencing points, Swimming points, iding points, Laser-run points

$X_{5}$ : Riding points, $X_{6}$ : Laser-run points 
Third, the converted score of fencing was most affected in both men's and women's events after revision.

Especially the men's game was more affected than the women's game. Fourth, scoring system of swimming was least affected in both men's and women's events. After the 2012 London Olympics, Heck (2014) emphasized the importance of track and swimming, which require basic physical fitness as one way for modern pentathlon not to disappear in the Olympics. He also emphasized that the gap in athletic performance reduced depending on the score's traits and system when the basic physical strength is central in the sport. In addition, the research of Parisi et al., (2015) revealed that the competition records at modern pentathlon was the result of long-term training on the basis of physical strength. Han \& Choi (2016) reported that there was no big gap or difference between the two groups in the records of swimming, riding and track sports according to comparative study of Korean modern pentathlon athletes. Le Meur et al., (2010) showed there could be a big gap or difference in skills in sports such as fencing and shooting compared to other sports including running and swimming. We believe that modern pentathlon is a game that measures basic physical strength as well as the skills of the players. Recently, however, there has been a tendency to emphasize the relative importance of competing in technology rather than measuring physical strength in modern pentathlon events (Fonseca et al., 2014).

In particular, the result analysis of this study showed that the relative importance of fencing competitions was more emphasized in modern pentathlon. In contrast, the relative importance of swimming events in modern pentathlon has been weakened, which might be one of the reasons why there has been no improvement of athletes swimming records in modern pentathlon. Athletes participating in modern pentathlon may not be interested in practicing and improving their records in swimming competitions, which are of low relative importance. For the development of modern pentathlon, athletes should play every game seriously and sincerely, and sports researchers and administrators should show institutional support so that they can perform well. Therefore, establishing a fair scoring system for the five major events that make up modern pentathlon is essential, and the current swimming competition scoring system needs a revision.

\section{Conclusion}

The study was based on the records of the official competition which were provided by UIPM for 6 years. This study's goal is figuring out the relationship between scores for each category of modern pentathlon such as fencing, swimming, riding, laser-run and final rankings, followed by comparing the relative importance of each event, which we studied using the records before and after the revision and based on the scoring system.

This study showed that modern pentathlon had emphasized relatively more technical factors than basic physical strength. This study revealed the relative importance of fencing, in which technical factors were important, was also higher than that of other events in the modern pentathlon. The relative importance of each competition was compared, with the results being fencing, laser-run, riding and swimming in order, which was for both men's and women's events. Fencing, in particular, showed the highest influence on both men's and women's events before and after the revision, while swimming had the lowest influence. A decrease in the relative importance of swimming has led to a decrease in game records. According to this study, establishing a fair scoring system for the five major events that make up modern pentathlon is essential, and the current swimming competition scoring system needs a revision. Therefore, this study shows that the current modern pentathlon scoring system distorts the relative importance of the constituent events, suggesting the need to fix it for the development of modern pentathlon. This study may contribute to revising the current points scoring system of UIPM by analyzing the relative 
importance of each event of modern pentathlon. We also believe that a follow-up study on scoring methods that can properly evaluate player's performance in modern pentathlon is necessary.

\section{References}

Berry, W. D. (1993). Understanding regression assumptions (Vol. 92). Sage Publications.

Choi, K. J., Kim, Y. S., Lee, Y. S., Park, J. W., \& Yeom, H. B. (2014). A study on the improvement of sports science support system to improve the performance of national players. Korea Institute of sports science, Research Report.

Dabbagh, H., \& Edgar, A. (2020). Talking about 'Fairness' in Football and Politics: The Case of Navad. Sport, Ethics and Philosophy, 1-14.

Federration, K. M. P. (2018). UIPM Competition Rules And Regulations Guidelines. 2018. Available(http:// www.pentathlon.or.kr/upload/rule/uipm_comp_rul es_and_reg_2018_a5_v2).

Fonseca Junior, S. J., Loureiro, L. L., Feital, E. M., \& Pierucci, A. P. T. (2014). Impact of detraining on anthropometry of adolescent pentathletes. Revista Brasileira de Medicina do Esporte, 20(5), 398-401.

Han, D. R., \& Choi, H. J. (2016). Comparisons of performances before and after the rule changes in the Modern Pentathlon. The Korean Journal of Physical Education, 55(4), 541-550.

Heck, S. (2014). A sport for everyone? Inclusion and exclusion in the organisation of the first Olympic Modern Pentathlon. The International Journal of the History of Sport, 31(5), 526-541.

Hughes, M., \& Franks, I. M. (Eds.). (2004). Notational analysis of sport: Systems for better coaching and performance in sport. Psychology Press.

Kim, H. S. (2012). Normative Justification of Fair Play in Sport: with Priority Given to Financial Fair Play. The Korean Society for the Philosophy of Sport, Dance \& Martial Arts, 20(1), 33-53.

Kuzon, W., Urbanchek, M., \& McCabe, S. (1996). The seven deadly sins of statistical analysis. Annals of plastic surgery, 37, 265-272.

Le Meur, Y., Hausswirth, C., Abbiss, C., Baup, Y., \& Dorel, S. (2010). Performance factors in the new combined event of modern pentathlon. Journal of sports sciences, 28(10), 1111-1116.

Lee, J. H. (2016). The Meaning Research of Moral Value of Sport. Korean society of sport and leisure studies, 65, 21-30.

Lee, J. H. (2019). A Legal Review of Rule of Violation in Sports with the Foul Play Game as the subject of the rules of basketball games. Korean Law Association, 19(2), 497-520.

Lim, C. H., Yoon, J. R., Jeong, C. S., Kim, Y. S., Lim, C. H., Yoon, J. R., ... \& Kim, Y. S. (2018). An Analysis of the Performance Determinants of Modern Pentathlon Athletes in Laser-run, A NewlyCombined Event in Modern Pentathlon. Exercise Science, 27(1), 62-70.

MacRae, S. A. (2020). Rules in games and sports: why a solution to the problem of penalties leads to the rejection of formalism as a useful theory about the nature of sport. Journal of the Philosophy of Sport, 47(1), 49-62.

Michell, J. (2008). Is psychometrics pathological science?. Measurement, 6(1-2), 7-24.

Moh, Y. S., Han, S. T., Yeon, K. P. \& Kang, H. C. (2015). A Study on Variable Importance Measures in Multiple Regression Analysis. Journal of The Korean Data Analysis Society, 17(6), 2981-2990.

Parisi, A., Tranchita, E., Magini, V., Fabrizi, E., Cerulli, C., \& Cardelli, G. (2015). The evolution of modern pentathlon following the introduction of the latest changes to the rules. Medicina dello Sport, 68(1), 121-7.

Park, J. J., \& Park, S. S. (2012). The understanding of referees decision factor and improvement way in Kumdo competition. Journal of Korean Alliance of Martial Arts. Volume14, (3), 149-161.

Peranginangin, Y., \& Alamsyah, A. (2017). Multiple regression to analyse social graph of brand 
awareness. Telkomnika, 15(1), 336.

Stevens, S. S. (1951). Mathematics, measurement, and psychophysics. In S. S. Stevens. (Ed.) Handbook of
Experimental Psychology. New York: Wiley.

UIPM. (2017). https://www.uipmworld.org/search?search _phrase=rule. 